\title{
Meningioma of the pineal region: a surgical series of 10 cases
}

\author{
Alexander Nikolaevich Konovalov, M.D., D.Sc., Aldo Spallone, M.D., \\ and David Iraklevich Pitzkhelauri, M.D.
}

Institute of Neurosurgery "N. N. Burdenko," Moscow, Russia

\begin{abstract}
$\checkmark$ Ten cases of meningioma of the pineal region were histologically verified at a single institution during an 8-year period. These represented $0.3 \%$ of 3061 intracranial meningiomas, as well as $6.2 \%$ of 164 pineal tumors. Patients were predominantly women. Symptoms and signs of increased intracranial pressure were most common, whereas Parinaud's syndrome was observed in only one case. Computerized tomography (CT) was the main diagnostic test used in the present series. It usually revealed a hyperdense mass with high-intensity contrast enhancement and a calcified mass eccentrically located at the periphery, which returned to its central location postsurgically and was likely to represent a calcified pineal gland. Magnetic resonance imaging was performed in the more recent cases and confirmed the suspicion raised by CT of a meningioma with a calcified mass at its periphery. Surgery was performed using an occipital transtentorial microsurgical approach with the patient placed in the semisitting position. Gross-total tumor removal was achieved in all cases, although this required sacrifice of the vein of Galen in six patients. Venous occlusion was performed only after adequate intraoperative verification of functional occlusion and blood flow diversion from the galenic system and had no consequences in any case but one. This latter patient had an infiltrative meningioma that was removed at the expense of intraoperative sacrifice of the two internal cerebral veins, as well as unavoidable trauma to the region of the quadrigeminal plate. All the remaining patients improved postsurgery, and only one had a permanent visual field deficit as a result of the surgical approach. Pineal meningiomas represent a rare subgroup of pineal tumors that can be treated surgically with reasonably good results. Sacrifice of major basal veins may be required to achieve radical tumor removal and can be tolerated by the patient provided that functional occlusion of the galenic system, as indicated by preoperative angiography, is verified during surgery.
\end{abstract}

\section{KEY WORDS - pineal region - meningioma - microsurgical treatment • vein of Galen occlusion • computerized tomography}

$\mathrm{T}$ UMORS of the pineal region are uncommon and represent less than $1 \%$ of intracranial tumors in different reported case studies from either European or American centers. ${ }^{2,3,14}$ Meningiomas represent a rare subgroup among those lesions, approximately $8 \%$ in different series. ${ }^{14,30}$ These tumors are of obvious interest because of their benign biological behavior and potential cure by radical surgery. On the other hand, the location of these lesions close to vital structures such as choroidal arteries, the vein of Galen, and the midbrain makes radical surgery a formidable challenge.

In the last 8 years, approximately 160 tumors of the pineal region have been surgically treated at the Institute of Neurosurgery "N. N. Burdenko," for the most part by the senior author (A.N.K.) Ten of these tumors (6.2\%) were meningiomas. These cases represent the basis for the present report.

\section{Clinical Material and Methods}

\section{Patient Population}

The 10 cases discussed were observed between 1987 and 1994 and represent $6.2 \%$ of 164 pineal tumors treated and approximately $0.3 \%$ of the 3061 intracranial meningiomas histologically verified in the same period at our institution.
All 10 patients were adult (average age 52 years, range 41-60 years) and most were female (female/male ratio 7:3). The duration of the preadmission clinical history ranged from 3 to 36 months and averaged 18 months. Clinical symptoms and signs (Table 1) were chiefly related to disturbances of coordination and ocular abnormalities. Interestingly, two cases exhibited hearing loss that normalized after surgery, whereas Parinaud's syndrome, a typical sign of pineal tumors, occurred in only one case in the present series.

\section{Diagnostic Tests}

The diagnostic testing protocol included angiography in most cases, computerized tomography (CT) in all, and magnetic resonance (MR) imaging in the most recent ones. Surgery was performed via an occipitobasal microsurgical approach using paramedial tentorial incision, with the patient placed in the semisitting position.

\section{Results}

\section{Radiographic Studies}

Angiography was performed in seven cases and showed a typical "meningioma blush" $\overline{1 n}$ the region of the quadrigeminal plate (Fig. 1). The tumor blood supply derived 
TABLE 1

Symptoms and signs in 10 patients with meningioma of the pineal region

\begin{tabular}{lcc}
\hline \multicolumn{1}{c}{ Symptoms } & No. of Cases & Percent \\
\hline headache \&/or papilledema & 6 & 60 \\
mental changes & 5 & 50 \\
hearing impairment & 3 & 30 \\
gait disturbances & 6 & 60 \\
cerebellar signs & 5 & 50 \\
pyramidal weakness & 3 & 30 \\
pupillary abnormalities & 3 & 30 \\
diplopia & 3 & 30 \\
upward gaze paresis & 1 & 10 \\
\hline
\end{tabular}

from the tentorial artery in four cases, whereas in one case only choroidal vessels fed the lesion. In the remaining two cases no dural vessel seemed to supply the tumor; however, at surgery the lesion was found to be attached to the falcotentorial junction. Adequate angiographic demonstration at the vein of Galen and straight sinus was often very difficult.

On CT scans a homogeneous lesion with strong contrast enhancement was seen occupying the pineal region (Fig. 2 left). In all cases a small calcification was demonstrated at the periphery of the lesion and never inside it. Routine postoperative CT scans (Fig. 2 right) showed that the calcified structure reassumed a central position following gross-total tumor removal. This confirmed our impression at surgery that this small calcification was in fact the pineal gland, which was left untouched during tumor removal.

Magnetic resonance imaging was performed in six cases and showed a hyperintense mass that enhanced with administration of gadolinium contrast material (Fig. 3). The size of the tumors, as calculated from diagnostic images and verified at surgery, varied from $3 \times 2.8 \mathrm{~cm}$ to $6 \times 4.2 \mathrm{~cm}$.

\section{Surgical Treatment}

With the patient in the semisitting position, we used the occipitotranstentorial approach from the nondominant side, which allowed the tumor to be readily identified after careful lateral retraction of the occipital lobe. Brain retraction seemed even easier when we placed the patient in the three-quarter prone position (Case 8). However, the unfamiliar view of the microsurgical anatomy provided by this position made gross-total tumor removal with preservation of the basal veins, which we eventually achieved, a formidable challenge.

After paramedial tentorial incision, a full view of the lesion was obtained, and the tumor could be debulked using an ultrasonic aspirator. Eventual mobilization of the reduced lesion allowed tumoral feeding vessels to be identified and coagulated to reduce intraoperative blood loss. The tumor was excised in a piecemeal fashion. Identification and preservation of the vein of Galen was often very difficult and actually impossible in six cases. In five of these cases we occluded the vein of Galen to excise tumor matrix. In all these patients functional occlusion of the vein of Galen with or without the straight sinus, as

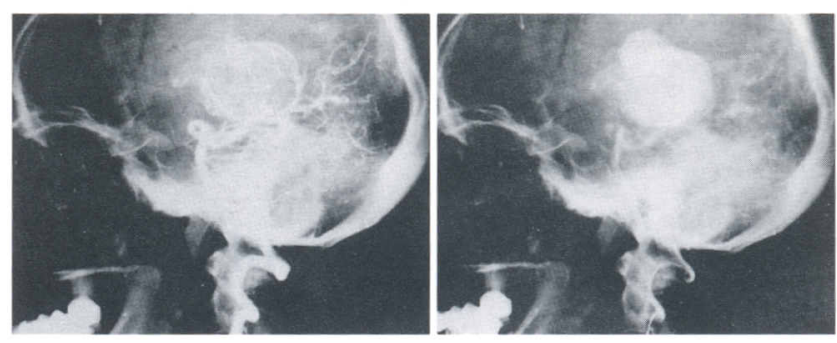

FIG. 1. Case 3. Vertebral angiograms. Left: Angiogram showing early arterial phase. Tumor vascularization comes primarily from the choroidal arteries. Right: Late arterial-capillary phase angiogram showing the tumor blush. The deep veins are hardly visualized.

observed angiographically, was verified intraoperatively prior to deliberate venous occlusion. In one case (Case 4) all basal veins had to be occluded because they were extensively infiltrated by the tumor (see Discussion). This case was the only one in the present group with a poor outcome. No dural attachment was detected in two cases. In the remaining cases, tumor attachment was extensively coagulated, and the vein of Galen and the straight sinus left undisturbed.

Intraoperative blood loss was not significant in five cases. In the remaining five, blood loss ranged from 400 to $1900 \mathrm{ml}$. The average operating time was 5 hours.

The present case material is briefly summarized in Table 2. Postoperative hemianopsia occurred in three cases (Cases 1, 2, and 9) but totally regressed in two (Cases 1 and 9). One patient was comatose for several weeks after removal of a malignant infiltrative meningioma but later was able to open her eyes and follow simple commands. She was discharged to a nursing home and lost to followup review.

\section{Follow-Up Results}

Follow-up review ranged from 3 months to 9 years in the remaining nine cases and averaged 3 years. One case (Case 2) was left with permanent homonymous hemianopsia, although he was able to lead a nearly normal life. The remaining patients were practically neurologically intact, and no one showed signs of recurrence.

\section{Discussion}

\section{Surgical Approaches to the Pineal Region}

A direct surgical approach to the pineal region has been considered almost impossible in the past. ${ }^{17,22,23,31}$ However, the results of surgical treatment of pineal masses have improved considerably in recent years, particularly after Stein $^{30}$ and Piatt and Campbell ${ }^{18}$ revived the supracerebellar approach originally introduced by Krause. ${ }^{10}$ However, satisfactory results have also been reported recently by authors using a supratentorial basal-occipital route, as a modification after introduction of microsurgical techniques from the classic approach described by Poppen and Marino, ${ }^{20}$ although retraction of the occipital lobe poses a risk of permanent visual deficits postoperatively. ${ }^{18}$ More recently Ausman, et al. ${ }^{4}$ described a new approach to the 


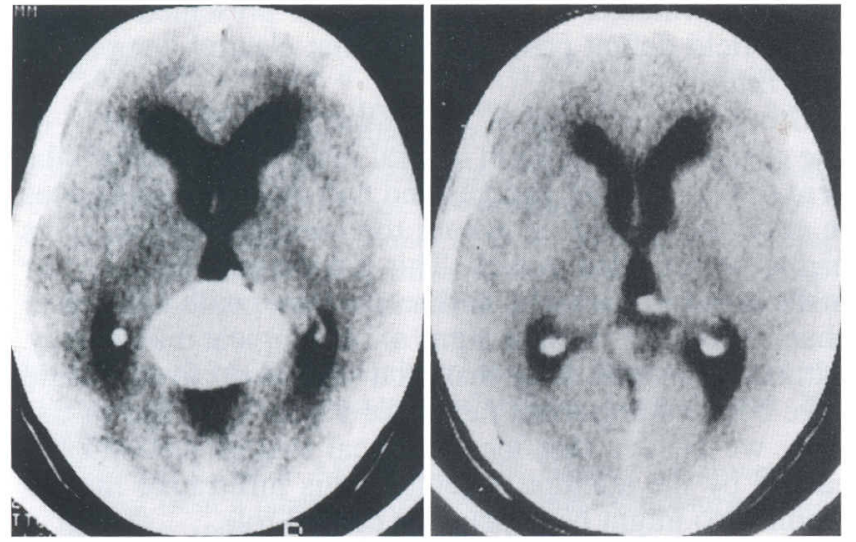

FIG. 2. Case 7. Computerized tomography (CT) scans. Left: Postcontrast CT scan demonstrating a round, well-defined hyperdense mass with strong contrast enhancement. A calcification is eccentrically located at the periphery of the tumor. Right: Postoperative CT scan showing that the tumor is no longer visible. The calcified pineal gland has returned to its central location.

pineal region along the medial side of the occipital lobe, in which the patient was placed in a position that they called "three-quarter prone." Advantages of this position included: 1) no need for retraction of the occipital lobe, which falls by gravity; 2) comfort of the surgeon, whose arms can be rested on the patient's shoulder; and 3) no risk of air embolism as in other positions used for surgery of the pineal masses. ${ }^{4}$ The main disadvantage is the angle of view provided by this approach, because visualization of the contralateral vein of Rosenthal may be quite problematic and orientation is definitely less easily maintained in comparison to midline approaches.

\section{Definition of Pineal Meningiomas}

Meningiomas of the pineal region represent a rare subgroup of pineal tumors, in which a direct surgical approach represents the primary management option.

There is some disagreement in the literature, which is admittedly very scanty, as to which meningioma developing in the quadrigeminal cistern and/or in the posterior third ventricle should be actually defined as a pineal meningioma. Piatt and Campbell, ${ }^{18}$ and Obrador, et al. ${ }^{14}$ included in this definition meningiomas arising from the falcotentorial junction. Stein, ${ }^{30}$ in his discussion of Piatt and Campbell's article, suggested that only meningiomas arising from the velum interpositum and freely lying in the pineal region should be included in this group. This opinion is shared by others. ${ }^{24}$

Surprisingly, if one looks again at the reported statistics, the percentage of pineal meningiomas in the whole group of pineal tumors does not differ significantly in the cases reported by Obrador, et al., ${ }^{14}$ and Stein, ${ }^{30}$ although their definitions of pineal meningioma appear to be quite different.

We believe that meningiomas lying in the region of the pineal gland and with the radiological appearance of actual pineal tumors should be considered to be pineal meningiomas, although they arise from the falcotentorial junction, to which they appear to be minimally attached. Using
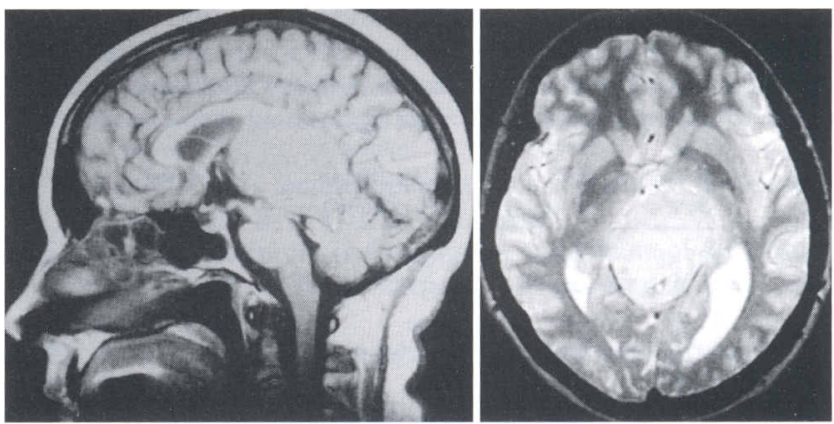

FIG. 3. Sagittal (left) and axial (right) $\mathrm{T}_{1}$-weighted magnetic resonance images showing a homogeneous oval mass with no surrounding edema. Note the eccentric calcified pineal gland.

this definition, the percentage of meningiomas identified in the group of pineal tumors in our study appears to be close to that reported in the aforementioned large case studies. , 2,6,14,20,28,30 We observed three types of pineal meningiomas in our patients: 1) a free-lying mass without dural attachment; 2) tumors minimally attached to the tentorium and/or the falx without functional compromise of the venous system; 3) tumors with minimal dural attachment but with occlusion of the galenic system. We did not consider falcotentorial meningiomas with little secondary extension into the pineal region.

\section{Clinical Characteristics of Pineal Meningiomas}

Meningiomas tend to occur in older patients (at 40 vs. 20 years of age on average) when compared with other pineal tumors, and show an approximate $2: 1$ female predominance, unlike other pineal tumors such as germinomas. The clinical history is usually insidious, and a long interval often passes between the start of symptoms and diagnosis. Unlike the other more common histological subtypes of pineal tumors, symptoms and signs related to increased intracranial pressure such as headache, papilledema, gait disturbances, and mental changes are most common in pineal meningiomas.9,12,13,19,25,26 Pupillary abnormalities and/or upward gaze paresis are uncommon; these symptoms were seen in two of the 10 cases in the present study. This matches the data reported in the literature and clearly distinguishes pineal meningiomas from other pineal masses; the incidence of eye abnormalities in the latter is significantly higher. ${ }^{7,13,16,22,23,29}$ Hearing impairment likely related to local tumor interference with central auditory pathways ${ }^{21}$ occurred in three of the patients in our study (30\%), as well as in $15 \%$ of the cases reported in the literature. $^{5}$

\section{Neuroimaging Studies in Pineal Meningiomas}

The introduction of CT technology has greatly facilitated the diagnosis of pineal masses. Although preoperative differential diagnosis remains very difficult by its nature, several criteria may be helpful in distinguishing the rare meningioma from other pineal tumors. ${ }^{24}$

In all cases presented here, we found calcifications on CT scans; these calcifications were characteristically located on the margins of the lesion and never inside it. We wonder if the age of patients with pineal meningiomas 


\section{TABLE 2}

Summary of pre- and postoperative KPS scores and basal vein occlusion in 10 patients with meningioma of the pineal region*

\begin{tabular}{rcclcr}
\hline \hline Case & $\begin{array}{c}\text { Age } \\
\text { (yrs), } \\
\text { No. }\end{array}$ & $\begin{array}{c}\text { Preop } \\
\text { KPS } \\
\text { Score }\end{array}$ & $\begin{array}{c}\text { Intraop } \\
\text { Basal Vein } \\
\text { Occlusion }\end{array}$ & $\begin{array}{c}\text { Follow-Up } \\
\text { Period } \\
\text { (mos) }\end{array}$ & $\begin{array}{c}\text { Postop } \\
\text { KPS } \\
\text { Score } \dagger\end{array}$ \\
\hline 1 & $43, \mathrm{M}$ & 20 & none & 88 & 100 \\
2 & $56, \mathrm{~F}$ & 30 & VG & 87 & 80 \\
3 & $41, \mathrm{~F}$ & 30 & none & 43 & 90 \\
4 & $60, \mathrm{~F}$ & 60 & VG, bilat ICVs & 5 & 20 \\
5 & $57, \mathrm{~F}$ & 50 & VG & 27 & 90 \\
6 & $55, \mathrm{~F}$ & 30 & VG, rt VR, SR & 26 & 80 \\
7 & $40, \mathrm{~F}$ & 50 & VG, SR & 22 & 90 \\
8 & $52, \mathrm{M}$ & 60 & none & 12 & 100 \\
9 & $42, \mathrm{~F}$ & 40 & VG & 9 & 90 \\
10 & $51, \mathrm{M}$ & 30 & none & 3 & 60 \\
\hline
\end{tabular}

* ICV = internal cerebral vein; KPS = Karnofsky performance scale; $\mathrm{SR}=$ sinus rectus (straight sinus) $; \mathrm{VG}=$ vein of Galen; $\mathrm{VR}=$ vein of Rosenthal.

$\uparrow$ Postoperative KPS scores were obtained at the time of the last followup review

played a role in this occurrence, which may be considered a distinctive sign for pineal meningioma and be helpful in the preoperative differential diagnosis. Postoperative CT scanning confirmed our intraoperative impression that calcification actually represented a calcified pineal gland that was left untouched during the surgical intervention.

Cerebral angiography is helpful in delineation of the relationship between the tumor and the important surrounding vessels. However, because pineal meningiomas may sometimes derive their blood supply from posterior choroidal vessels only, a preoperative differential diagnosis with other pineal region tumors may be impossible. Careful consideration of the venous phase is of obvious importance for surgical planning, because failure of opacification of major basal veins may indicate that intraoperative venous occlusion might be tolerated by the patient. Magnetic resonance imaging may offer further information to facilitate the correct preoperative diagnosis of the tumor type. However, the so-called "tail sign," usually considered characteristic of meningiomas in other locations, ${ }^{30}$ was not detected in any of our patients. We did not perform MR angiography in any of our 10 patients, but we are convinced that this examination may play a crucial role in the diagnostic workup of patients with pineal meningiomas.

\section{Surgical Treatment of Pineal Meningiomas}

We treated the majority of our patients using a parietooccipital microsurgical approach with the patient in the semisitting position, as described by Jamieson. ${ }^{8}$ In one of the most recent cases we adopted the three-quarter prone position described by Ausman, et al. ${ }^{4}$ Preoperative suspicion of pineal meningioma prompted us to use these approaches instead of the supracerebellar route that we routinely use for pineal tumors.

Stein ${ }^{30}$ warned about the risk of using a supratentorial approach for these tumors. Actually, only one of the patients in the present series developed a permanent postoperative hemianopsia as a result of retraction of the occipi- tal lobe, whereas two other patients presented with a visual field deficit postsurgically that cleared completely with time.

Gross-total removal of the lesion required sacrifice of one or more basal veins in several cases. This involved the vein of Galen in six patients and had major consequences in only one patient, in whom the internal cerebral veins had to be occluded as well. This patient was the only one in the present series who harbored a tumor with infiltrative characteristics as well as signs of histological malignancy. Although it seems clear that total venous occlusion could have been an important factor for a poor outcome in this case, we believe that local surgical trauma unavoidably caused by the attempt to remove this infiltrative meningioma also might have played a crucial role.

Identification and coagulation of the feeding vessels was usually performed as the first surgical step. Subsequently the tumor was debulked with an ultrasonic aspirator and removed piecemeal. The tumor capsule was excised and the tumor attachment was excised whenever possible, or extensively coagulated. As already mentioned, sacrifice of one or more major veins and/or of the straight sinus was unavoidable in most cases to achieve total tumor removal. The feasibility of surgical occlusion of the galenic system in cases of falcotentorial meningioma has been mentioned in the literature, although reports have been rare until now. ${ }^{15,27}$ With the exception of the case mentioned above, the results were good to excellent, and no recurrences were observed after an average of 3 years of follow-up review.

\section{Conclusions}

Pineal meningiomas represent a rare subset of pineal region masses, whose clinical characteristics, although distinct from those of pineal tumors as a whole, do not allow a preoperative diagnosis of type. Neuroimaging diagnostic tools, such as CT, MR, and angiography, may provide further information to help the surgeon correctly address the preoperative suspicion of pineal meningioma.

Surgery is the only management modality in these cases, because these tumors are benign and encapsulated. However, the direct approach poses a considerable risk in this region, and management policy must be individualized, taking into consideration other factors such as age and general condition of the patient, presenting symptoms, and presence of hydrocephalus. Some authors ${ }^{11}$ have suggested that direct surgery be reserved for patients suffering from symptoms of local pressure from the tumor, particularly if they are not responding to alternative measures for reducing intracranial pressure.

On the other hand, careful microsurgical technique and experience with surgery of the pineal region may allow very satisfactory long-term results, as was true in our series.

It is noteworthy that a significant proportion of our patients tolerated the deliberate occlusion of the vein of Galen, which was performed to obtain radical removal of the lesion. However, surgical interruption of basal veins should be performed only after intraoperative verification of functional occlusion and blood flow diversion from the vein of Galen. 


\section{References}

1. Abay EO II, Laws ER Jr, Grado GL, et al: Pineal tumors in children and adolescents: treatment by CSF shunting and radiotherapy. J Neurosurg 55:889-895, 1981

2. Araki C, Matsumoto S: Statistical reevaluation of pinealoma and related tumors in Japan. J Neurosurg 30:146-149, 1969

3. Asari S, Maeshiro T, Tomita S, et al: Meningiomas arising from the falcotentorial junction. Clinical features, neuroimaging studies, and surgical treatment. J Neurosurg 82:726-738, 1995

4. Ausman JI, Malik GM, Dujovny M, et al: Three-quarter prone approach to the pineal-tentorial region. Surg Neurol 29: 298-306, 1988

5. DeMonte F, Zelby AS, Al-Mefty O: Hearing impairment resulting from a pineal region meningioma. Neurosurgery 32: $665-668,1993$

6. Donat JF, Okazaki H, Gomez MR, et al: Pineal tumors: a 53year experience. Arch Neurol 35:736-740, 1978

7. Hase U, Hock H, Schindler E: Tumoren der pinealisregion: Teil I. Neurologische und neuroradiologische Symptomatik bei 23 Patienten. Neurochirurgia 22:107-117, 1979

8. Jamieson KG: Excision of pineal tumors. J Neurosurg 35: $550-553,1971$

9. Kirschberg GJ, Epstein I, Strasberg Z, et al: Normal-pressure hydrocephalus due to tentorial meningioma. Can Med Assoc J 115:154-155, 1976

10. Krause F: Operative Freilegung der Vierhugel nebst Beobachtungen über Hinbrisk und Dekompression. Zentralb Chr 53: 2812-2819, 1926

11. Lazar ML Comment on: Piatt JH, Campbell GA: Pineal region meningioma: report of two cases and literature review. Neurosurgery $12: 375-376,1983$

12. Lecuire J, Dechaume JP: Les méningiomes de la fosse cérébrale postérieure. Neurochirurgie 17 (Suppl 2):1-147, 1971

13. Nakayama K, Miysaka Y, Ohwada T, et al: [Meningioma in the pineal region-report of a case and review of the literature.] Neurol Med Chir 20:265-271, 1980 (Jpn)

14. Obrador S, Soto M, Gutierrez-Diaz JA: Surgical management of tumours of the pineal region. Acta Neurochir 34:159-171, 1976

15. Odake G: Meningioma of the falcotentorial region: report of two cases and literature review of occlusion of the Galenic system. Neurosurgery 30:788-794, 1992

16. Papo I, Salvolini U: Meningiomas of the free margin of the tentorium developing in the pineal region. Neuroradiology 7: $237-243,1974$
17. Pendl G: Pineal and Midbrain Lesions. New York: SpringerVerlag, 1985, pp 103-116

18. Piatt JH Jr, Campbell GA: Pineal region meningioma: report of two cases and literature review. Neurosurgery 12:369-375, 1983

19. Pinney EL Jr: A tentorial meningioma manifested by mental signs. Dis Nerv Syst 27:583-585, 1966

20. Poppen JL, Marino R Jr: Pinealomas and tumors of the posterior portion of the third ventricle. J Neurosurg 28:357-364, 1968

21. Posner M, Horrax G: Eye signs in pineal tumors. J Neurosurg 3:15-24, 1946

22. Rand RW, Lemmen LJ: Tumors of the posterior portion of the third ventricle. J Neurosurg 10:1-18, 1953

23. Ringertz N, Nordenstam H, Flyger G: Tumors of the pineal region. J Neuropathol Exp Neurol 13:540-561, 1954

24. Roda JM, Pérez-Higueras A, Oliver B, et al: Pineal region meningiomas without dural attachment. Surg Neurol 17:147-151, 1982

25. Sachs E Jr: Meningiomas with dementia as the first and presenting feature. J Ment Sci 96:998-1007, 1950

26. Sachs E Jr, Avman N, Fisher RG: Meningiomas of pineal region and posterior part of $3 \mathrm{rd}$ ventricle. J Neurosurg 19: 325-331, 1962

27. Sakaki S, Shiraishi T, Takeda S, et al: Occlusion of the great vein of Galen associated with a huge meningioma in the pineal region. Case report. J Neurosurg 61:1136-1140, 1984

28. Sano K: Diagnosis and treatment of tumours in the pineal region. Acta Neurochir 34:153-157, 1976

29. So SC: Pineal tumours: a clinical study of 23 cases. Aust $\mathbf{N}$ Z J Surg 46:75-79, 1976

30. Stein BM: Surgical treatment of pineal tumors. Clin Neurosurg 26:490-510, 1979

31. Suzuki J, Wada T, Kowada M: Clinical observations on tumors of the pineal region. J Neurosurg 19:441-445, 1962

32. Wray SH: The neuro-ophthalmologic and neurologic manifestation of pinealomas, in Schmidek H (ed): Pineal Tumors. New York: Masson, 1977, pp 21-59

Manuscript received December 4, 1995.

Accepted in final form April 22, 1996.

Address reprint requests to: Aldo Spallone, M.D., Division of Neurosurgery, University of Rome, "Tor Vergata," Via O. Raimondo, Rome, Italy. 